DOI: $10.12957 /$ e-mosaicos.2020.44534

\title{
ENSINO, APRENDIZAGEM E ARTE: RASTREAMENTOS DE UM ARQUIVO
}

\author{
TEACHING, LEARNING AND ART: MAPPINGS OF AN ARCHIVE
}

\author{
CAMARGO, Jeferson ${ }^{1}$ \\ CAVALHEIRO, Bruno Mallmann² \\ MUNHOZ, Angelica Vier ${ }^{3}$
}

\begin{abstract}
RESUMO
O presente artigo resulta de uma investigação realizada por bolsistas de iniciação científica (PIBIC/CNPq), do Grupo de Pesquisa Currículo, Espaço, Movimento (CEM/Univates). O propósito foi mapear, arquivar e dar visibilidade à produção engendrada pela pesquisa, no período de 2013-2018, de modo a compreender os seus movimentos e articulações com o campo empírico. Para tal feito, operou-se com a noção de arquivo, a partir de Foucault (2008) e Derrida (2001), entre outros. Tomaram-se como descritores as palavras ensino, aprendizageme arte, tendo em vista que essas noções percorreram os estudos e investigações do Grupo. Os procedimentos de arquivamento e arquivização foram considerados a partir de Aquino \& Val (2018), com o objetivo de organizar os achados, ao mesmo tempo em que se revitalizam os materiais encontrados. Por fim, analisar tal arquivo não implicou interpretação de resultados conclusivos, mas oscilações, modulações que remetem a novas visibilidades.
\end{abstract}

PalaVRAS-ChaVe: Grupo CEM; arquivo; ensino; aprendizagem; arte.

\begin{abstract}
This paper has stemmed from an investigation carried out by scientific research fellows (PIBIC/CNPq) from the Curriculum, Space, Movement Research Group (CEM/Univates). The aim was to map, file and bring visibility to the production enabled by the research in the 20132018 period, aiming to understand its moves and articulations with the empirical field. In order to do that, we worked with the notion of archive, based on Foucault (2008) and Derrida (2001), among others. The following words were used as descriptors: teaching, learning and art, considering that such notions were present in the studies and investigations performed by the Research Group. The procedures of archiving and archivization were taken from Aquino \& Val (2018), with the purpose of organizing the findings and, at the same time, revitalizing the materials that we have found. Finally, the analysis of such archive has not involved the interpretation of conclusive results, but rather oscillations, modulations that lead to new visibilities.
\end{abstract}

KEYWORDS: CEM Research Group; archive; teaching; learning; art.

\footnotetext{
1 Universidade do Vale do Taquari (UNIVATES). Lajeado, RS, Brasil. e-mail: jeefcamargo@gmail.com

2 Universidade do Vale do Taquari (UNIVATES). Lajeado, RS, Brasil. e-mail: bruno.cavalheiro@universo.univates.br

${ }^{3}$ Universidade do Vale do Taquari (UNIVATES). Lajeado, RS, Brasil. ORCID: https://orcid.org/00000002-2644-043X e-mail: angelicavmunhoz@gmail.com
} 
DOI: $10.12957 / \mathrm{e}-\mathrm{mosaicos} .2020 .44534$

\section{DO QUE SE TRATA}

O presente artigo deriva de uma investigação realizada por bolsistas de iniciação científica (PIBIC/CNPq), cujo propósito foi mapear, arquivar e dar visibilidade à produção engendrada pelo Grupo de Pesquisa Currículo, Espaço, Movimento (CEM), no período de 2013 a 2018. Dos documentos colhidos nos espaços, entrevistas, anotações coletadas em diário de bordo, observações e produções científicas realizadas pelo Grupo CEM, acredita-se que já existe um arquivo. Contudo, não se trata de um arquivo no sentido apenas de registro histórico, de soma de textos guardados, mas daquilo que, segundo Foucault (2008), determina o que deve ser conservado - e o que deve ser abandonado.

Durante o percurso do Grupo de Pesquisa, o mote das investigações foi pensar as questões do ensino, da aprendizagem e da arte. Essas noções foram utilizadas como descritores para operar com o arquivo. Assim, apropriando-se dos materiais já colhidos no campo empírico e das produções já realizadas pelo Grupo CEM, buscou-se rastrear, cruzar dados, mostrar em que medida as noções de ensino, aprendizagem e arte aparecem, se repetem, compõem e estão implicadas nas investigações do referido Grupo.

\section{OS PERCURSOS DO GRUPO CEM}

O Grupo de Pesquisa Currículo, Espaço, Movimento (CEM/CNPq/Univates), vinculado ao Programa de Pós-graduação em Ensino da Universidade do Vale do Taquari - Univates, foi criado em março de 2013. Com apoio do Conselho Nacional de Desenvolvimento Científico e Tecnológico (CNPq), foi desenvolvido o seu primeiro projeto de pesquisa, que vigorou de 2013 a 2016 e teve como objetivo investigar o currículo em diferentes espaços escolares e não escolares, bem como seus movimentos escolarizados e não escolarizados.

A partir de 2017, iniciaram-se novos projetos de pesquisa, com apoio da Fundação de Amparo à Pesquisa do Estado do Rio Grande do Sul (FAPERGS) e do Conselho Nacional de Desenvolvimento Científico e Tecnológico (CNPq); os projetos consistem em investigar os processos de ensinar e aprender produzidos por práticas educativas e artísticas em espaços escolares e não escolares. Tais projetos vêm operando com as seguintes questões de pesquisa: como a aprendizagem e o ensino estão sendo pensados nos espaços escolares e não escolares? De que modo os espaços escolares e não escolares produzem práticas educativas e artísticas em meio aos processos de ensinar e aprender?

O pensamento da Filosofia da Diferença, a partir dos autores Gilles Deleuze \& Félix Guattari, Friedrich Nietzsche e Michel Foucault, é tomado, desde o início, como aporte teórico da investigação do Grupo de Pesquisa. As discussões curriculares também se tornaram centrais, assim como as teorizações curriculares pósestruturalistas propostas por pensadores brasileiros, como Sandra Corazza, Tomaz 
DOI: 10.12957/e-mosaicos.2020.44534

Tadeu, Alfredo Veiga-Neto, entre outros, foram fundamentais para a construção do plano conceitual da pesquisa.

Em termos de aporte metodológico, a pesquisa aproximou-se da genealogia de Michel Foucault (2002, 2005), a partir de um enfoque qualitativo-genealógico, e, mais recentemente, de procedimentos exploratórios experimentais. Para Foucault, a genealogia constitui-se em uma forma "[...] de fazer da história um uso que a liberte para sempre do modelo, simultaneamente metafísico e antropológico, da memória. Trata-se de fazer da história uma contramemória e de desdobrar, consequentemente, uma forma totalmente diferente do tempo." (FOUCAULT, 2005, p.277). Nesse sentido, para o Grupo CEM, a construção dos conceitos de currículo, ensino e aprendizagem, práticas educativas, arte e educação como os compreendemos hoje passa a ser questionada. Para isso, trata-se de descrever os acontecimentos discursivos, os seus encadeamentos, os lugares institucionais nos/dos quais determinadas práticas são produzidas. Por outra via, os procedimentos exploratórios-experimentais (CORAZZA, 2012) permitem problematizar os clichês, formas, sentidos, conhecimentos, identificando a imagem dogmática de pensamento que lhes corresponde em seus pressupostos explícitos e implícitos de doxa e senso comum (HEUSER, 2016). Tratase, portanto, de efetuar dois movimentos: uma dimensão crítica e genealógica em que "[...] o pesquisador diagnostica as séries constituintes, disparatadas e paradoxais, que integram um sistema metaestável, constituído de puras intensidades heterogêneas" (CORAZZA, 2012, p.11); uma dimensão exploratório-experimental, na qual o pesquisador "[...] se introduz no interior de outro nível de ideias, de uma outra experiência do pensamento, solicitando forças que são potências de uma terra incógnita jamais antes conhecida" (CORAZZA, 2012, p.12). Em síntese, por um lado, busca-se compreender as condições de possibilidade em que cada noção, conceito, prática, é constituído e operado nos campos empíricos da pesquisa; por outro lado, propõem-se determinadas práticas e discussões com os participantes-partícipes desses campos de investigação, por meio de propostas de extensão, a fim de pensar em outras práticas e experimentações dos temas em discussão.

Espaços escolares e não escolares tornaram-se o campo empírico do Grupo CEM desde o início, incluindo escolas, museus e Ongs. Até 2016, foram três espaços escolares - uma escola em Bogotá/Colômbia, uma escola pública na cidade de Lajeado/RS e uma escola Ambiental na cidade de Ilópolis/RS - e dois espaços não escolares - uma ONG em Lajeado/RS e um museu de arte em POA/RS. Atualmente, a partir de 2017, o campo empírico do Grupo CEM consiste em: três escolas públicas do município de Lajeado/RS (Escola Municipal Porto Novo, Escola Estadual Érico Veríssimo e Escola Estadual Manuel Bandeira); quatro espaços de Arte (Museu de Arte do Rio/RJ, Fundação Iberê Camargo - POA/RS, Fundação Vera Chaves Barcellos - Viamão/RS e Serviço Social do Comércio - SESC, Lajeado/RS). Cabe destacar que a escolha de investigar o currículo em espaços não escolares - sobretudo, por esses espaços não escolares se constituírem em instituições de arte - não foi neutra. Acredita-se que, estando tais espaços atravessados pela arte, são capazes de produzir deslocamentos, recusando-se às fixações que de algum modo estratificam os movimentos do currículo. Contudo, de forma alguma, afirma-se que os espaços não escolares são sinônimos de 
DOI: $10.12957 /$ e-mosaicos.2020.44534

deslocamentos e movimentos curriculares mais flexíveis, pois as instituições, de modo geral, são capturadas por movimentos escolarizantes.

Assim, durante os seis anos de atuação do Grupo CEM, procuraram-se investigar: a) as particularidades dos espaços de investigação - escolas e museus - e as questões relativas que os permeiam; b) as questões conceituais e teóricas que dão sustentação aos processos de ensinar e aprender por meio de práticas educativas e artísticas. Tais problematizações permitiram aproximarmo-nos mais intensivamente das noções de ensino, aprendizagem e arte, assim como buscar compreender de que modo tais noções permeiam os currículos e as práticas educativas de espaços escolares e não escolares.

\section{OPERAR COM O ARQUIVO}

Trata-se de operar com um arquivo - o arquivo produzido pelo Grupo de Pesquisa Currículo, Espaço, Movimento durante o período de 2013 a 2018. Para tal feito, buscou-se aproximação do conceito de arquivo junto aos autores Michel Foucault (2008) e Jacques Derrida (2001), entre outros.

Na obra Arqueologia do Saber, Michel Foucault (2008) afirma que o arquivo

é o que faz com que todas as coisas ditas não se acumulem indefinidamente em uma massa amorfa, não se inscrevam, tampouco, em uma linearidade sem ruptura e não desapareçam ao simples acaso de acidentes externos, mas que se agrupem em figuras distintas, componham umas com as outras, segundo relações múltiplas [...]. (FOUCAULT, 2008, p. 147).

O arquivo, para Foucault, não é um lugar de onde se extraem fatos, um depósito de letras mortas, mas um conjunto de regras que permite o aparecimento, a ativação e o apagamento de determinados enunciados. Assim, na contramão de uma história linear das ideias, dos fatos e das coisas, Michel Foucault (2008) compreende o arquivo como um sistema de discursividades que se transforma, se modifica, se atualiza e nunca se esgota.

Contudo, a noção de arquivo elucida outros entendimentos ou, como afirmam Aquino e Val (2018, p.45), "a noção de arquivo comporta uma acentuada polissemia.". Assim, se tomarmos a concepção de Jacques Derrida (2001), veremos que o arquivo tem sua origem no grego e "abriga em si mesmo esta memória do nome arkhê." (DERRIDA, 2001, p. 12). Para o autor, arkhê:

[...] designa ao mesmo tempo o começo e o comando. Este nome coordena aparentemente dois princípios em um: o princípio da natureza ou da história, ali onde as coisas começam - princípio físico, histórico ou ontológico -, mas também o princípio da lei, ali onde os homens e os deuses comandam, ali onde se a exerce a autoridade, a 
DOI: $10.12957 /$ e-mosaicos.2020.44534

ordem social, nesse lugar a partir do qual a ordem é dada - princípio nomológico. (DERRIDA, 2001, p. 12, grifos do autor).

Segundo Derrida, "o sentido de arquivo, seu único sentido, vem para ele do arkheîon grego, inicialmente uma casa, um domicílio, um endereço, a residência dos magistrados superiores, os arcontes, aqueles que comandavam." (DERRIDA, 2001, p.13). Esses arcontes, guardiões dos arquivos, eram os responsáveis pela segurança do depósito e do suporte dos arquivos, e "cabiam-Ihes também o direito e a competência hermenêutica. Tinham o poder de interpretar os arquivos." (DERRIDA, 2001, p.13). Os arquivos foram se acumulando, ficando em domínio de um seleto grupo, que deles poderia fazer uso e enunciar o que eles continham, suas significações, suas leis, suas verdades. Essa arquivologia teve sua massificação na Idade Média, como relatam Chagas e Pereira:

Na Europa, foi sobretudo a partir da Idade Média que se organizaram os grandes arquivos nacionais. Em decorrência do grande número de documentos acumulados no passado e da produção cada vez maior de novos documentos, aperfeiçoou-se a Arquivologia, que consiste no conjunto de técnicas de organização e manipulação de arquivos. (CHAGAS; PEREIRA. 2011, p. 320).

Também podemos olhar para as noções mais duras de arquivo, como a mencionada no Dicionário de Terminologia Arquivística (BRASIL, 2005), e encontraremos que o arquivo é o "conjunto de documentos produzidos e acumulados por uma entidade coletiva, pública ou privada, pessoa ou família, independente da natureza do suporte." (BRASIL, 2005, p.27). Assim, em meio a diversas definições do arquivo, voltamos novamente para Aquino e Val (2018) a fim de compreendermos ainda mais a sua potencialidade:

A reboque das definições aqui evocadas, o arquivo teria o condão de constituir ou, ao contrário, extinguir atos, dizeres e comportamentos pregressos. Ou seja, um instrumento potente da forja histórica, tanto no que se refere à composição de determinado passado, quanto no que diz respeito à invenção do próprio presente. (AQUINO; VAL, 2018, p. 46).

Para Aquino e Val, operar com arquivo implica dois procedimentos analíticos arquivamento e arquivização -, de maneira que "[...] a obstinação documentária está para o primeiro procedimento [arquivamento] do mesmo modo que a imaginação recriadora está para o segundo [arquivização]." (AQUINO; VAL, 2018, p.48). Portanto, se 0 arquivamento diz respeito à reorganização dos achados, a arquivização possibilita ativar, revitalizar e recriar o próprio arquivo. 
DOI: $10.12957 /$ e-mosaicos.2020.44534

\section{DO PROCEDIMENTO ARQUIVÍSTICO}

Diante da produção desenvolvida pelo Grupo de Pesquisa CEM, encontramos um considerável arquivo, o qual necessita de arquivamento e de arquivização, pois, como afirma Foucault (2008), o arquivo é um sistema de enunciados que se legitimam e modificam ao serem manuseados.

Para tal propósito, em um primeiro momento, foi realizado um procedimento de arquivamento por ano de atuação do Grupo CEM. Esse arquivamento "corresponde, portanto, à tarefa de reordenação transversal das fontes, por meio das (re)montagens das lacunas discursivas em torno de determinados problemas concretos abrigados no e pelo arquivo." (AQUINO; VAL, 2018, p. 49). A imersão no material selecionado voltou-se, inicialmente, ao arquivamento das noções de ensino, aprendizagem e arte, as quais foram usadas como descritores para a busca. Os materiais rastreados consistiram em artigos, capítulos de livros, textos completos publicados em anais de eventos, entrevistas, anotações coletadas em diário de bordo e observações nos espaços de investigação. Tal arquivamento foi realizado por meio de tabelas, organizadas a partir do ano e do número de vezes que os autores ou descritores (ensino, aprendizagem e arte) apareciam nos materiais investigados. As tabelas foram organizadas a partir de: a) anos e autores/artistas estudados pelo Grupo CEM; b) descritores ensino, aprendizagem e arte. As tabelas podem ser observadas abaixo.

Tabela 1. Anos e autores/artistas

\begin{tabular}{|l|l|l|}
\hline $\mathbf{2 0 1 3}$ & $\mathbf{2 0 1 4}$ & $\mathbf{2 0 1 5}$ \\
\hline Autores/Artistas & Autores/Artistas & Autores/Artistas \\
Alfredo Veiga-Neto & Ana Maria Hoepers Preve & Ana Maria Hoepers Preve \\
Félix Guattari & André Severo & André Lepecki \\
Gilles Deleuze & Artur Barrio & Betina Guedes \\
Michel Foucault & Dino Segura & Charles Baudelaire \\
Roland Barthes & Félix Guattari & Clarice Lispector \\
Sandra Mara Corazza & Francis Laÿs & Dino Segura \\
Tomaz Tadeu da Silva & Friedrich Nietzsche & Félix Guattari \\
& Gilles Deleuze & Gaston Bachelard \\
& Guilherme Carlos Corrêa & Geisha Fontaine \\
& Jérôme Bel & Georges Perec \\
& Joseph Beuys & Gilles Deleuze \\
& Lygia Clark & Giorgio Agamben \\
& Mario Garcia Torres & Guilherme Carlos Corrêa \\
& Michel Foucault & Jérôme Bel \\
& Richard Long & Laura H. Dalla Zen \\
& Roland Barthes & Lygia Clark \\
& Silvio Gallo Corazza & Manoel de Barros \\
& Suely Rolnik & Michel Foucault \\
& Tomaz Tadeu da Silva & Roland Barthes \\
& William Kentridge & Sandra Corazza \\
& Silvio Gallo \\
& Sophie Calle \\
& Tomaz Tadeu da Silva \\
\hline
\end{tabular}


DOI: $10.12957 /$ e-mosaicos.2020.44534

\begin{tabular}{|c|c|c|}
\hline 2016 & 2017 & 2018 \\
\hline $\begin{array}{l}\text { Autores/Artistas } \\
\text { Alfredo Veiga-Neto } \\
\text { Alice Casimiro Lopes } \\
\text { Alicia M. Catalano de Bonamino } \\
\text { Almerindo Janela Afonso } \\
\text { Alvaro M. Hypolito } \\
\text { Brasil Bernstein } \\
\text { Carlos Alonso Barbosa Oliveira } \\
\text { Charles Baudelaire } \\
\text { Elizabeth Macedo } \\
\text { Éric Marty } \\
\text { Félix Guattari } \\
\text { Flávia Obino Corrêa Werle } \\
\text { Friedrich Nietzsche } \\
\text { Gilles Deleuze } \\
\text { Giorgio Agambem } \\
\text { Gustavo Zmbenedetti } \\
\text { Jan Masschlein } \\
\text { Jérôme Bel } \\
\text { José Augusto Pacheco } \\
\text { Júlia Varela } \\
\text { Júlio Groppa Aquino } \\
\text { Laurence Bardin } \\
\text { Leyla Perrone-Moisés } \\
\text { Licínio C. Lima } \\
\text { Luciana Gruppelli Loponte } \\
\text { Maarten Simons } \\
\text { Marcos Bauer } \\
\text { Mathieu Lindon } \\
\text { Michael Young } \\
\text { Michel Foucault } \\
\text { Murray Schafer } \\
\text { Nikolas Rose } \\
\text { Paula Sibilia } \\
\text { Peter Miller } \\
\text { Roberto Machado } \\
\text { Roland Barthes } \\
\text { Ron Mueck } \\
\text { Rosane Azevedo Neves da Silva } \\
\text { Roseline Barbour } \\
\text { Rui Canário } \\
\text { Sandra Mara Corazza } \\
\text { Sandra Zákia Sousa } \\
\text { Silvio Gallo } \\
\text { Silvio Gallo } \\
\text { Simone Barreto Anadon } \\
\text { Stephen Ball } \\
\text { Sylvio Gadelha } \\
\text { Thomas S. Kuhn } \\
\text { William Kentridge }\end{array}$ & $\begin{array}{l}\text { Autores/Artistas } \\
\text { Alice Casimiro Lopes } \\
\text { Ana Paula Crizel } \\
\text { Angélica Vier Munhoz } \\
\text { Clarice Lispector } \\
\text { Cristiano Bedin da Costa } \\
\text { D. M. Albuquerque Júnir } \\
\text { David Paulo Ausubel } \\
\text { Edgardo Castro } \\
\text { Eduardo Passos } \\
\text { Elizabeth Macedo } \\
\text { Félix Guattari } \\
\text { Franz Kafka } \\
\text { Friedrich Wilhelm Nietzsche } \\
\text { Gaston Bachelard } \\
\text { Gaudêncio Frigotto } \\
\text { George Gaskell } \\
\text { Georges Perec } \\
\text { Gert Biesta } \\
\text { Gilcilene Dias da Costa } \\
\text { Gilles Deleuze } \\
\text { Gonçalo M. Tavares } \\
\text { Gustavo Fischman } \\
\text { Haroldo de Campos } \\
\text { Honoré de Balzac } \\
\text { Ismail Xavier } \\
\text { Jacopo Crivelli Visconti } \\
\text { Jan Masschlein } \\
\text { Jordi Sierra I Fabra } \\
\text { Jorge Larrosa } \\
\text { José Gil } \\
\text { Júlio Groppa Aquino } \\
\text { Lúcia Santaella } \\
\text { Luciana Gruppelli Loponte } \\
\text { Luciano Bedin da Costa } \\
\text { Marcel Martin } \\
\text { Maria Bueno Fischer } \\
\text { Maria Manuela Alves Garcia } \\
\text { Markus Banks } \\
\text { Marlucy Alves Paraíso } \\
\text { Marten Simons } \\
\text { Martin W. Bauer } \\
\text { Maximo Lamela Adó } \\
\text { May Benatar } \\
\text { Michel de Certeau } \\
\text { Michel Foucault } \\
\text { Paula Sibilia } \\
\text { Phillipe Dubois } \\
\text { Regina Orgler Sordi } \\
\text { Roberto Machado } \\
\text { Roland Barthes }\end{array}$ & $\begin{array}{l}\text { Autores/Artistas } \\
\text { Adriana Piscitelli } \\
\text { Angela Davis } \\
\text { Antonio Maia } \\
\text { Betina Sílva Guedes } \\
\text { Fernanda Dorneles da Silva } \\
\text { Friedrich Nietzsche } \\
\text { Gilles Deleuze } \\
\text { Haroldo de Campos } \\
\text { Italo Calvino } \\
\text { Jandiro Adriano Koch } \\
\text { Jérôme Bel } \\
\text { Jorge Larrosa } \\
\text { Julio Groppa Aquino } \\
\text { Leticia Lorenzoni Lasta } \\
\text { Margarita Rosa Gaviria Mejia } \\
\text { Michel Foucault } \\
\text { Priscila Rigoni } \\
\text { Robert Castel } \\
\text { Robert Doherty } \\
\text { Roland Barthes } \\
\text { Rosmari Terezinha Cazarotto } \\
\text { Sandra Mara Corazza } \\
\text { Tatiana Luiza Rech } \\
\text { Tomaz Tadeu } \\
\text { Walter Benjamin }\end{array}$ \\
\hline
\end{tabular}


DOI: $10.12957 /$ e-mosaicos.2020.44534

\begin{tabular}{|l|l|l|}
\hline & Rosa Maria Bueno Fischer & \\
& Sandra Mara Corazza & \\
& Sandra Salas & \\
& Silvia Tedesco & \\
& Sílvio Gallo & \\
& Sophie Calle & \\
& Suzana Feldens Schwertner & \\
& Tomaz Tadeu da Silva & \\
& Vilém Flusser & \\
& Virgínia Kastrup & \\
& Walter Benjamin & \\
\hline
\end{tabular}

Tabela 2. Ano e descritores

\begin{tabular}{|c|c|c|}
\hline Ano & Noção & $\begin{array}{c}\text { Número de vezes que } \\
\text { apareceu }\end{array}$ \\
\hline \multirow[t]{3}{*}{2013} & Ensino & 63 \\
\hline & Aprendizagem & 47 \\
\hline & Arte & 9 \\
\hline \multirow[t]{4}{*}{2014} & Noção & $\begin{array}{c}\text { Número de vezes que } \\
\text { apareceu }\end{array}$ \\
\hline & Ensino & 66 \\
\hline & Aprendizagem & 63 \\
\hline & Arte & 62 \\
\hline \multirow[t]{4}{*}{2015} & Noção & $\begin{array}{c}\text { Número de vezes que } \\
\text { apareceu }\end{array}$ \\
\hline & Ensino & 46 \\
\hline & Aprendizagem & 67 \\
\hline & Arte & 78 \\
\hline
\end{tabular}




\begin{tabular}{|c|c|c|}
\hline 2016 & Noção & $\begin{array}{c}\text { Número de vezes que } \\
\text { apareceu }\end{array}$ \\
\hline & $\begin{array}{l}\text { Ensino } \\
\text { Aprendizagem } \\
\text { Arte }\end{array}$ & $\begin{array}{c}67 \\
112 \\
113\end{array}$ \\
\hline 2017 & Noção & $\begin{array}{c}\text { Número de vezes que } \\
\text { apareceu }\end{array}$ \\
\hline & $\begin{array}{l}\text { Ensino } \\
\text { Aprendizagem } \\
\text { Arte }\end{array}$ & $\begin{array}{l}44 \\
84 \\
88\end{array}$ \\
\hline 2018 & Noção & $\begin{array}{c}\text { Número de vezes que } \\
\text { apareceu }\end{array}$ \\
\hline & $\begin{array}{l}\text { Ensino } \\
\text { Aprendizagem } \\
\text { Arte }\end{array}$ & $\begin{array}{l}28 \\
47 \\
31\end{array}$ \\
\hline
\end{tabular}

Ao olhar inúmeras vezes para o processo de arquivamento construído, buscouse criar um procedimento de arquivização para dar visibilidade e atualidade aos achados. Esse processo implicou costurar alguns dados, construir algumas séries, dar visibilidade a algumas noções centrais que aparecem, se repetem, retornam e se diferenciam.

\section{O QUE NOS MOSTRAM OS ACHADOS?}

A lógica arquivística é sempre da ordem do indeterminado e inconcluso, de maneira que os ordenamentos e classificações são sempre variáveis, e novas classificações são sempre passíveis de serem criadas. Do mesmo modo, a forma como olhamos e analisamos os achados não implica interpretações e resultados fidedignos, mas oscilações, modulações, variáveis que remetem sempre a novas visibilidades.

Do arquivamento realizado, partiu-se para a segunda tarefa, que consistia em criar um procedimento de arquivização, o qual "oportuniza o encontro não somente com os papéis inertes da história, mas com potências ativas, na qualidade de pontos de inflexão que mobilizam e produzem ressonâncias, dada sua capacidade de 
DOI: $10.12957 /$ e-mosaicos.2020.44534

produzirem desvio." (AQUINO; VAL, 2018, p. 50). Portanto, buscou-se acompanhar as modulações, os movimentos, as mudanças conceituais realizadas nesses seis anos de trajetória do Grupo CEM.

A partir dos achados, foi possível perceber que há uma variação bastante grande de autores ao longo dos seis anos de pesquisa e que esse número foi crescente a cada ano. Alguns desses autores são centrais e tomados como referências nos estudos do Grupo de Pesquisa, tais como os clássicos Michel Foucault, Gilles Deleuze, Félix Guattari, Friedrich Nietzsche e Roland Barthes, entre outros; por isso, aparecem em todos os anos, ou seja, fazem parte de estudos longitudinais do Grupo de Pesquisa. Há também comentadores desses autores clássicos que aparecem listados sequencialmente, pois serviram de revisão teórica para o Grupo CEM. Como, inicialmente, o foco do Grupo era o currículo, pode-se perceber que muitos autores das teorias curriculares pós-estruturalistas se fazem presentes no primeiro ano da pesquisa. A partir de 2014, os literários e artistas começam a ser estudados, o que coincide com a aproximação mais gradativa e intensiva dos espaços de arte. Também literários e artistas se tornam intercessores para se pensar o currículo, assim como as práticas educativas e artísticas.

Em relação às noções de ensino, aprendizagem e arte, pode-se perceber que, embora tais noções sejam centrais em todo o processo do Grupo de Pesquisa, a noção de arte inicialmente aparece de forma tímida e só vai ganhar maior força a partir de 2014 , como pode ser observado no quadro 2 . Esse fato se deve aos próprios resultados da pesquisa, pois, à medida que se percebe a importância dos movimentos curriculares na sua relação com os espaços, a centralidade de um currículo atravessado por experiências curriculares mais inventivas e artísticas ganha força e engendra os novos rumos do Grupo CEM. Outro motivo que faz com que a noção de arte passe a ter maior visibilidade nos materiais arquivados é o fato de, em 2015, o Grupo CEM firmar uma parceria com o Museu de Arte do Rio, o que implicou, nos anos de 2016 e 2017, a realização de residências pedagógicas no espaço de arte e subsequentes publicações. Em meio a esse contexto, a arte, a partir de 2014, começa a tornar-se um operador importante para o Grupo de Pesquisa, atingindo seu ápice em 2016, o que vai resultar, inclusive, na centralidade dos objetivos de pesquisa do novo projeto, que começa a vigorar em 2017. Esses movimentos também podem ser percebidos no gráfico abaixo.

CEM $2013-2018$

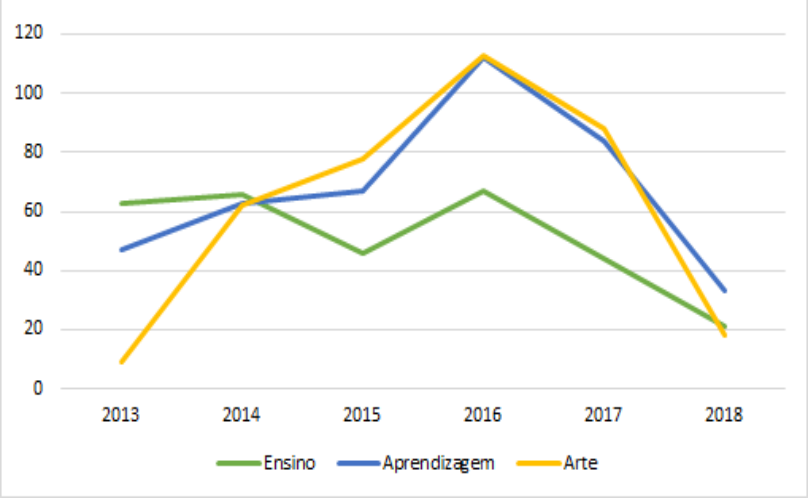

Fig.1 Ensino, aprendizagem e arte de 2013 a 2018 no Grupo CEM 
DOI: $10.12957 /$ e-mosaicos.2020.44534

Igualmente, podemos perceber um gradativo aumento do aparecimento da noção de aprendizagem até 2016. Acredita-se que tal crescimento se deve ao fato de o Grupo de Pesquisa estreitar seus laços com alguns espaços escolares, sobretudo com a Escuela Pedagógica Experimental (EPE), de Bogotá/Colômbia, onde um grupo de pesquisadores fez uma imersão pedagógica, realizando entrevistas, observações e inúmeras publicações de suas práticas. Cabe destacar que a EPE é uma escola com um currículo diferenciado, com um grande investimento no processo de aprendizagem dos seus alunos. Em relação a essa escola, vale mencionar: "comumente, a pesquisa no espaço da escola é associada a um protagonismo discente, uma vez que o aluno tem a oportunidade de construir seu conhecimento por meio da busca, da experimentação, das trocas com os colegas e o meio." (HATTGE et al., 2016, p.13). Ainda, um subprojeto do Grupo CEM, com apoio do CNPq, é desenvolvido por uma das pesquisadoras no período de 2014 a 2016, intitulado "A escola e as novas configurações da contemporaneidade: a voz de estudantes concluintes do ensino médio e fundamental". Tal projeto envolvia perguntar a estudantes de uma das escolas parceiras, quais as funções da escola hoje. Por meio de registros fotográficos, os estudantes falavam da escola, incluindo as perspectivas do ensino e das aprendizagens envolvidas. Esses resultados, assim como as publicações geradas da investigação, também compuseram o arquivo referente. Enfim, acredita-se que esses encontros com escolas resultaram na gradativa aparição da noção de aprendizagem nos arquivos pesquisados. Desse modo, percebe-se que aprendizagem e arte se tornam noções centrais para o Grupo de Pesquisa, do ano de 2015 até 2017, caminhando lado a lado.

A noção de ensino, por sua vez, permanece constante nas produções do Grupo, evidenciando articulações tanto com os espaços escolares quanto com os não escolares. Assim, mesmo que ela esteja presente nos estudos e investigações do Grupo ou no problema que passa a ser delineado a partir de 2016 - Como a aprendizagem e o ensino estão sendo pensados nos espaços escolares e não escolares? De que modo os espaços escolares e não escolares produzem práticas educativas e artísticas em meio aos processos de ensinar e aprender? -, ela não se torna uma noção tão veemente no arquivo investigado, o que não designa uma menor importância para os estudos do Grupo.

Por fim, pode-se observar que, no ano de 2018, as três noções - ensino, aprendizagem e arte - se encontram menos visíveis no arquivo do Grupo CEM. Tais evidências não significam um investimento menor do Grupo nos estudos relativos a tais noções, nem uma diminuição dos movimentos de investigação no campo empírico, ou mesmo uma redução da produção científica do CEM. Com efeito, os números apresentados em relação a 2018 mostram resultados parciais, visto que muito da produção desse ano se encontra em processo de publicação, não estando aqui contabilizada. 
DOI: $10.12957 /$ e-mosaicos.2020.44534

\section{CONSIDERAÇõES FINAIS}

Não coube ao presente artigo apresentar resultados conclusivos. Isso porque 0 Grupo de Pesquisa CEM segue com seus estudos e investigações, mas principalmente porque a investigação aqui visibilizada não tinha como premissa tal propósito. $O$ desafio que se impôs, portanto, foi o de criar um modo de tratamento específico do material, apontando para a constituição de alguns agrupamentos - estes compostos por autores e noções estudados e investigados ao longo de seis anos de trabalho de um grupo de pesquisa, o CEM -, a partir dos quais foi possível perceber algumas modulações, ramificações, movimentos de investigação.

Tal parece ser o propósito de operar com um arquivo: elucidá-lo, torná-lo vivo para que se possa olhá-lo de outras formas, compô-lo por meio de outros arranjos. Assim, a cada vez que manusearmos esse arquivo de pesquisa, poderemos atualizar as suas análises e, ao mesmo tempo, produzir novos rumos, que resultarão em diferentes arquivos, passíveis de interpretações plurais.

\section{REFERÊNCIAS}

AQUINO, Julio Groppa; VAL, Gisela Maria do. Uma ideia de arquivo: contributos para a pesquisa educacional. Pedagogía y Saberes, n. 49, 2018, p. 41-53.

BRASIL. Arquivo Nacional. Dicionário brasileiro de terminologia arquivística. Rio de Janeiro: Arquivo Nacional, n51, 2005.

PEREIRA, Ingridd Michelle Lopes; CHAGAS, Pedro Dolabela. Arquivo e memória: uma análise dos conceitos de arquivo segundo Michel Foucault e Roberto Gonzalez Echevarría. Vitória da Conquista: Fólio - Revista de Letras, v. 3, n. 2, 2011, p. 319 331.

CORAZZA, Sandra Mara. O drama do currículo: pesquisa e vitalismo de criação. In: IX ANPED SUL. 2012. Disponível em

<http://www.ucs.br/etc/conferencias/index.php/anpedsul/9anpedsul/paper/viewFile/ $128 /$

DERRIDA, Jacques. Mal de Arquivo: uma impressão freudiana. Rio de Janeiro: Relume Dumará, 2001.

FOUCAULT, Michel. Microfísica do poder. 16. Ed. Rio de Janeiro: Graal, 2001.

FOUCAULT, Michel. Nietzsche, a genealogia e a história. In: M. B. da Motta (org.) Ditos e escritos, II. Rio de Janeiro, Brasil: Forense Universitária, 2005. p. 260 -281. 
DOI: $10.12957 / \mathrm{e}-\mathrm{mosaicos} .2020 .44534$

FOUCAULT, Michel. A Arqueologia do Saber. 7 ed. Rio de Janeiro: Forense Universitária, 2008.

HATTGE, Morgana Domênica et al. A pesquisa movimentando o currículo: as potências do professor pesquisador. Paranaíba: Interfaces da Educ, v.6, n.18, p.178-196, 2016.

HEUSER, Ester M. D. Construcionismo de uma crítica genealógica de escrileituras. In: HEUSER Ester M. D. (org.). Caderno de notas 8: Ética e discussão política em meio à diferença e ao escrileitura. Cascavel: Edunioeste, 2016.

Recebido em 12 de agosto de 2019

Aceito em 02 de setembro de 2019

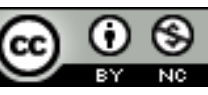

A e-Mosaicos Revista Multidisciplinar de Ensino, Pesquisa, Extensão e Cultura do Instituto de Aplicação Fernando Rodrigues da Silveira (CAp-UERJ) está licenciada com uma Licença Creative Commons - Atribuição-NãoComercial 4.0 Internacional.

Os direitos autorais de todos os trabalhos publicados na revista pertencem ao(s) seu(s) autor(es) e coautor(es), com o direito de primeira publicação cedido à e-Mosaicos.

Os artigos publicados são de acesso público, de uso gratuito, com atribuição de autoria obrigatória, para aplicações de finalidade educacional e não-comercial, de acordo com o modelo de licenciamento Creative Commons adotado pela revista. 